\title{
Optimization of extraction of polysaccharides from Suaeda salsa (L.) Pall. by ultrasonic: characterization, purification and antioxidant assessment
}

\author{
Jianxin $\mathrm{Fu}^{\text {a, b }}$, Jiawei Shao a , Meng Wang a , Guixiang Zhang ${ }^{\text {a, * }}$, and Yishan Fang ${ }^{\mathrm{b}, ~ *}$

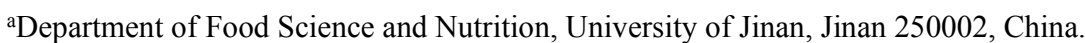 \\ bschool of Food Science and Engineering, Qilu University of Technology, Jinan 250353, People's Republic of China.
}

\begin{abstract}
Under optimal extraction conditions, characterization and antioxidant activity of polysaccharides from the Suaeda salsa (L.) Pall. were investigated. This was the first report that described the composition of the polysaccharide form this plant. Obviously, the yield of $2.19 \%$ for extraction of polysaccharides was obtained as ethanol volume fraction of $65 \%$, extraction time of $72 \mathrm{~min}$, ultrasound assisted power of $438 \mathrm{~W}$, and temperature of $85^{\circ} \mathrm{C}$, respectively. The structure study was carried out with FT-IR and SEM, and the chemical contents of carbohydrates, proteins, uronic acids and total flavonoids were measured in this study. The crude polysaccharides were purified into two components including SGP-1-1 and SGP-2-1. Moreover, the chemical composition analysis according to HPLC showed that it was viscous polysaccharide, which mainly contained glucose, mannose, xylose, galacturonic acid, glucuronic acid, fucose, rhamnose, arabinose, galactose, respectively. Besides, it was proved that the optimum polysaccharides possessed higher significant potentials $(P<0.05)$ in scavenging ability against $\mathrm{DPPH}, \mathrm{ABTS}^{+}$and hydroxyl radical.
\end{abstract}

\section{Introduction}

Suaeda salsa (L.) Pall. is a unique salt-tolerant herb of the chenopodiaceae, traditionally, it is a halophyte that growing mainly on sandy beaches and deserted in saline or alkaline soil. The plants are mainly distributed on the coast and north of the Oceania, China's Yellow River Delta beach area. Traditionally, it has been used as a medicine to reduce fever or consumption to increase salinity [1]. Due to the growth in saline soil, the trace elements and oils contents of seeds in Suaeda salsa. were much higher than that of soybean. In addition, the stems and leaves of it were also rich in amino acids, vitamins and minerals [2]. Typically, the aqueous extraction of Suaeda salsa. consisted essentially of salts and other components such as flavonoids and polyphenols, which signified that the extraction had certain antioxidant, bacteriostatic [3, 4] and antiinflammatory functions $[\underline{5}, \underline{6}]$. Besides, the coastal was the main areas for the growth of this plant. There was sufficient sunshine with large temperature difference between day and night, which was very conducive to the accumulation and transportation of anthocyanins and other secondary metabolites. So far, no studies have been reported to extract polysaccharides from Suaeda salsa.

Polysaccharides were a variety of poly-hydroxy macromolecular polymers that were widely found in cells of animals, plants and microorganisms. Generally, it was one of the basic substances that sustained life metabolism, and had physiological functions such as structural support, energy storage [7], and so on.
However, a large number of researches have consistently shown that polysaccharides had widely biological activities, including anti-tumor, anti-virus [8], anticoagulation, anti-oxidation [9], hypoglycemic and immunomodulatory properties. The study found that plant polysaccharides had obvious enhanced immune function, in which mainly increased it through the following aspects [10-12]: (1) by promoting the body to produce antibodies to enhance humoral immune function; (2) by promoting the proliferation of $\mathrm{T}$ and $\mathrm{B}$ lymphocytes to enhance the immune function of cells; (3) by increasing the phagocytic activity of macrophages to increase the number of macrophages; (4) by promoting increased transcriptional activity of cytokine mRNA to enhance biological activity of cytokines; (5) by altering the content and relative ratio of cellular signaling molecules such as cAMP, cGMP, NO, and $\mathrm{Ca}^{2+}$ in immune cells to regulate immune function. For example, asparagus polysaccharide can activate macrophage to release active medium NO and promote the expression of TNF- $\alpha$ and IL- 6 genes, which may be one of the ways for asparagus to enhance the body immunity. Therefore, researches on polysaccharides have been attracting attention in recent years, especially in extracting polysaccharides from salt-tolerant plants of Polygonaceae plants. For example, most of the polysaccharides extracted from Herba Pyrolae, Cordyceps and Lactobacillus, which consisted primarily of arabinose, glucose and galactose.

More recently, an acidic polysaccharide from the plant had been studied for anti-tumor activity. On this

\footnotetext{
* Corresponding author: fujx93@163.com
} 
basis, we carefully studied the extraction, purification, characterization and oxidation resistance in vitro. The main purpose of this study was to obtain maximum yield of polysaccharides from Suaeda salsa. The crude polysaccharides were purified by DEAE-52 cellulose and Sephadex G-100. Its physical characterization and chemical component analysis were performed by FT-IR, SEM and HPLC, and analysis of antioxidant properties were also carried out.

\section{Materials and methods}

\subsection{Plant materials}

Plants were harvested in July 2018 from Dongying (Long. $118^{\circ} 5^{\prime} \mathrm{E}$; Lat.38 $15^{\circ} \mathrm{N}$ ) of Shandong province in China. The plant was identified as Suaeda salsa (L.) Pall.by researcher X. Zhang (Department of Life Sciences, Shandong Normal University) which the sample was No.SD-s-2153327. The following regents were purchased from Sigma Chemical Co. (St. Louis, MO, USA) including DEAE-52 cellulose, 1-phenyl-3methyl-5-pyrazolone (PMP), Sephadex G-100, 1,1diphenyl-2-picrylhydrazyl (DPPH) and diammonium salt (ABTS). The TFA, methanol, hexane, ethanol and chloroform were all analytical purity.

\subsection{Extraction process of polysaccharide}

The whole plants were washed several times with water and frozen rapidly at $-37^{\circ} \mathrm{C}$ with liquid nitrogen to be dried. They were crushed by superfine grinding at 200 orders to be used. As shown in Fig. 1, Suaeda salsa. plants were treated several times with hexane and ethanol for $24 \mathrm{~h}$ at room temperature of $27^{\circ} \mathrm{C}$ in order to remove oily ingredients and pigments after they were washed and crashed. The rest of residue was used to extract crude polysaccharide by hot water with the ultrasound-assisted (Elmasonic S 40H, Sigen, Germany) extraction (UAE). The enrichment of extracting solution was centrifuged (at $4^{\circ} \mathrm{C}, 10000 \mathrm{r} / \mathrm{min}$ for $20 \mathrm{~min}$ ) [12] after precipitation of $95 \%(\mathrm{~V} / \mathrm{V})$ ethanol [13]. The precipitation was considered to be crude polysaccharide called SGP. The crude SGP solution was added with $25 \%(\mathrm{~V} / \mathrm{V})$ savage-chloroform shaking for $10 \mathrm{~min}$ to remove the protein of each group [14, 15]. Besides, it was dialyzed by membranes $(3 \mathrm{kDa})$ to remove salt ion and depigmented by resin (elution solvent: PBS $(0.1$ $\mathrm{mol} / \mathrm{L}, \mathrm{pH} 5.2$ ), $10 \mathrm{~mL} / \mathrm{min}$ ). Finally, the solution was freeze dried to provide the crude SGP, Suaeda salsa. polysaccharides.

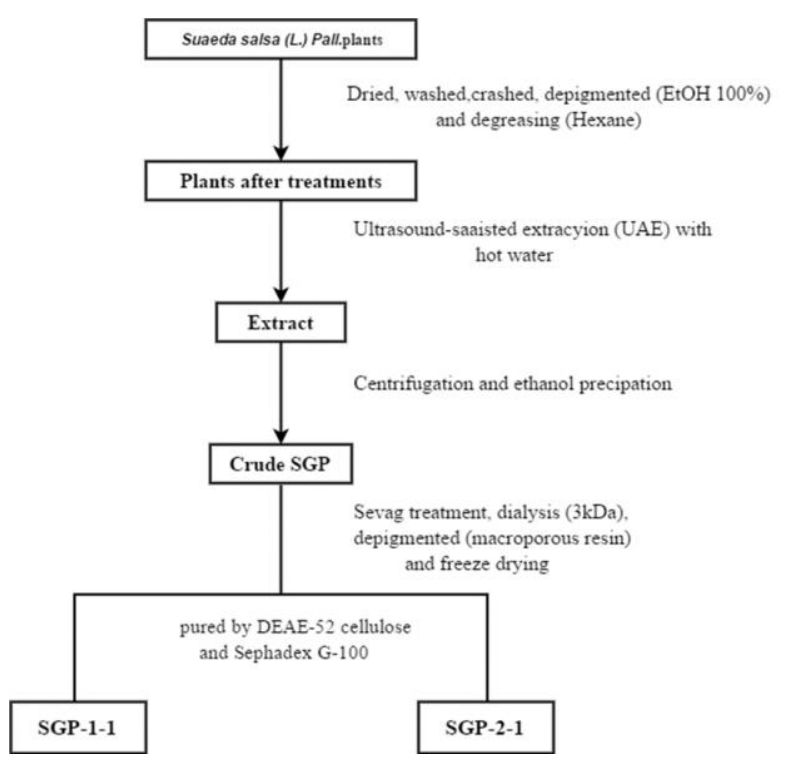

Fig.1 Steps for polysaccharide extraction of Suaeda salsa (L.) Pall. and purification

The yield percentage of polysaccharide was calculated as Eq. (1)

Polysaccharide yield $\left(Y_{(S F P, \%)}\right)=[1-$ Weight of extracted after $(\mathrm{g}) /$ Weight of the whole sample $(\mathrm{g})] \times 100$

\subsection{Experimental design of response surface methodology}

The influence of 4 factors process including ethanol volume fraction $\left(\mathrm{X}_{\mathrm{a}}: 50 \%, 65 \%\right.$, and $\left.80 \%\right)$, extraction time $\left(\mathrm{X}_{\mathrm{b}}: 50 \mathrm{~min}, 60 \mathrm{~min}\right.$, and $\left.70 \mathrm{~min}\right)$, ultrasound assisted power $\left(\mathrm{X}_{\mathrm{c}}\right.$ : $200 \mathrm{~W}, 320 \mathrm{~W}$, and $\left.440 \mathrm{~W}\right)$ and extraction temperature $\left(\mathrm{X}_{\mathrm{d}}: 65^{\circ} \mathrm{C}, 75^{\circ} \mathrm{C}\right.$, and $\left.85^{\circ} \mathrm{C}\right)$. The yield of carbohydrates under this extraction factors from Suaeda salsa. was recorded via the Box-Behnken experimental design (BBD) with 29 order experiments in order to obtain the best combination.

\subsection{Purification of crude SGP}

Crude SGP solution was centrifuged at $5000 \mathrm{rpm}$ for 10 min in order to remove insoluble portions after it was dissolved in distilled water with ultrasound assistance at $200 \mathrm{~W}$ and $40^{\circ} \mathrm{C}$. The SGP supernatant was then placed at room temperature $\left(28^{\circ} \mathrm{C}\right)$ for ion exchange chromatography on a DEAE-52 cellulose column $(2.6 \times 60 \mathrm{~cm})[16]$. The samples were separately eluted with distilled water, 0.2 and $0.4 \mathrm{M}$ sodium chloride $(\mathrm{NaCl})$ solution [17]. Data was recorded at $490 \mathrm{~nm}$ using sulfuric acid-phenol colorimetry when two completely separated fractions of SGP-1 and SGP-2 were collected, respectively. Then, the above components were concentrated and lyophilized. They were again purified by distillation on a Sephadex G-100 column $(1.6 \times 100$ $\mathrm{cm})$ [18]. As a result, they were finally separated and obtained: SGP-1 to SGP-1-1, SGP-2 to SGP-2-1, respectively. 


\subsection{Characterization of SGP}

\subsubsection{Determination of monosaccharide composition and molecular weights}

The monosaccharide composition of the SGP was analyzed by the method of PMP complexation according to published reports $[\underline{19}, \underline{20}]$. Sample $(5 \mathrm{mg} / \mathrm{mL}, 1 \mathrm{~mL})$ and TFA ( $4 \mathrm{M}, 4 \mathrm{~mL})$ was hydrolyzed at $120^{\circ} \mathrm{C}$ for $6 \mathrm{~h}$ under the confined environment, then it was added to methanol to remove excess TFA by rotary evaporation. The hydrolyzed monosaccharide with PMP $(0.5 \mathrm{M}, 1-$ phenyl-3-methyl-5-pyrazolone) expresses significant UV absorption at $290 \mathrm{~nm}$. The monosaccharide composition of SGP were analyzed by HPLC (Waters Breeze2, MA, USA) equipped with a UV detector (Waters 2489). The testing conditions were as follows: Venusil XBP $\mathrm{C}_{18}$ column (Waters Hewlett-Packed, MA, USA; 150 $\mathrm{mm} \times 4.6 \mathrm{~mm}, 5 \mathrm{um})$, column temperature at $27^{\circ} \mathrm{C}$, mobile phase via phosphate buffer $(0.2 \mathrm{~mol} / \mathrm{L}, \mathrm{pH} 6.9)$ acetonitrile $(82: 18, \mathrm{~V} / \mathrm{V})$, flow rate at $1.0 \mathrm{~mL} / \mathrm{min}$, wavelength at $290 \mathrm{~nm}$.

Multi-Angle Laser Light Scattering (MALLS) was used to determine the molecular weight and distribution of products, which was widely used in chemical material analysis and determination of biological macromolecules. The laser wavelength was $490 \mathrm{~nm}$ with quartz glass sample cell of MALLS. The data was recorded every $15^{\circ}$ during the scan interval of $0^{\circ}-180^{\circ}$ in dynamic light scattering experiment. The molecular weight of SGP and its particle size distribution can be tested according to this study.

\subsubsection{Infrared spectral (IR) and Scanning Electronic Microscopy (SEM) analysis of SGP}

Physical structure of SGP was performed by the Fourier transform infrared spectrophotometer (Thermo Electron Corp., Waltham, MA, USA). The mixture (with10 mg sample and $100 \mathrm{mg} \mathrm{KBr}$ ) was determined from 4000 $400 \mathrm{~cm}^{-1}$ (mid infrared region) to analyze the characterization of SGP $[\underline{21}, \underline{22}]$.

The scanning electronic microscopy of SGP has been reported by the scanning projection electron microscope (Thermo Prisma E., Waltham, MA, USA)[23, 24]. The SGP sample (2 mg) was detected on a tray to analyze the outside shape.

\subsection{Antioxidant activities}

The antioxidant activity of polysaccharide extracted from Suaeda salsa. was estimated according to 4 tests (including DPPH radical scavenging ability, $\mathrm{ABTS}^{+}$ radical scavenging ability, hydroxyl scavenging ability). Generally, the ascorbic acid was chosen as the standard sample.

\subsubsection{DPPH free radical scavenging activity}

The method of DPPH radical scavenging of polysaccharides from Suaeda salsa. were experienced via the reported essay [25]. $5 \mathrm{~mL}$ of DPPH solution $(0.1$ $\mathrm{mM}$ in ethanol) was mixed with different concentrates polysaccharide samples. Then, the mixture was reacted for $45 \mathrm{~min}$ in the dark at about $27^{\circ} \mathrm{C}$ and detected at around $517 \mathrm{~nm}$ via UV-vis (UV-2501PC). The experiment was conducted with ascorbic acid as the control. The DPPH radical scavenging rate of the sample was calculated according to Eq. (2):

DPPH free radical scavenging rate $(\%)=\left(1-\mathrm{Abs}_{\text {sample }} /\right.$ $\left.\mathrm{Abs}_{\text {control }}\right) \times 100$

\subsection{2 $\mathrm{ABTS}^{+}$radical scavenging activity}

The $\mathrm{ABTS}^{+}$radical scavenging ability test was mentioned by the previous report [26]. Different concentrations of polysaccharide solution $(1 \mathrm{~mL}$ with $\mathrm{pH}$ 7.1) was added into the blend, which included phosphate buffer $(2.5 \mathrm{~mL}$ at $0.2 \mathrm{M}$ with $\mathrm{pH} 6.6)$ and $1 \%$ potassium ferricyanide solution $(2.5 \mathrm{~mL}$ at $1 \%(\mathrm{~m} / \mathrm{v}))$. In order to fully react, all of these were protected at $50^{\circ} \mathrm{C}$ under water bath for $40 \mathrm{~min}$ in dark room. Then, the $\mathrm{ABTS}^{+}$ radical solution was added into trichloroacetic acid solution $(2.5 \mathrm{~mL}$ at $0.5 \mathrm{M})$, and the steady absorbance was obtained at $700 \mathrm{~nm}$. The $\mathrm{ABTS}^{+}$radical scavenging ability was tested at around $700 \mathrm{~nm}$ with the blend of 2.5 $\mathrm{mL}$ distilled water and ferric chloride solution $(0.5 \mathrm{~mL}$ at $0.05 \mathrm{mM}$ ) for $20 \mathrm{~min}$ after the initial mixing. The scavenging ability was indicated as Eq. (3):

Inhibitation $(\%)=\left(1-\mathrm{Abs}_{\text {sample }} / \mathrm{Abs}_{\text {control }}\right) \times 100$

\subsubsection{Hydroxyl radical scavenging activity}

In this study, $\mathrm{OH}^{-}$scavenging ability was estimated according to the method [27]. The reaction blend contained $\mathrm{FeSO}_{4} \cdot 7 \mathrm{H}_{2} \mathrm{O}$ solution $(2 \mathrm{~mL}$ at $6 \mathrm{mM})$, salicylic acid-ethanol solution $(2 \mathrm{~mL}$ at $7.5 \mathrm{mM}$ with $\mathrm{pH}$ $6.7), \mathrm{H}_{2} \mathrm{O}_{2}(2 \mathrm{~mL}$ at $8 \mathrm{mM})$ and different concentrates of polysaccharide solution $(2 \mathrm{~mL})$. Then, the blend was reacted for $30 \mathrm{~min}$ at about $37^{\circ} \mathrm{C}$ and measured at around $510 \mathrm{~nm}$ via UV-vis, ascorbic acid was used as the control. The scavenging ratio of the sample was expressed according to Eq. (4):

Scavenging percent $=\left[1-\left(\mathrm{A}-\mathrm{A}_{0}\right) / \mathrm{A}_{1}\right] \times 100$

$A=$ Absorbance of extract sample; $A_{0}=$ Absorbance of control (to replace sample with water); $\mathrm{A}_{1}=$ Absorbance of blank (to replace sample and $\mathrm{H}_{2} \mathrm{O}_{2}$ solution with water)

\subsection{Statistical analysis}

The BBD design and data analysis of RSM was calculated by Software Design-Expert (V12). The significance of diversities was assessed by one-way ANOVA analysis (with the significance of 2 level). All tests were repeated for three groups, with three parallel tests of each group $(n=3 \times 3)$. Data of triplicate parallel 
experiences were recorded as means \pm standard deviations by Microsoft Office (15.0).

\section{Results and discussion}

\subsection{Extraction yield of SGP}

\subsubsection{Effect of ethanol volume fraction on extraction yield of SGP}

In this test, the ethanol volume fraction was set as 35\%, $50 \%, 65 \%, 80 \%$ and $95 \%$. In the certain ethanol volume fraction range from $35 \%$ to $95 \%$, the total extraction yield of SGP was correlated significant $(P<0.05)$ with the condition in Fig.2 (A). The total extraction yield of SGP reached a maximum $1.76 \pm 0.09 \%$ when the ethanol volume fraction was $65 \%$. This situation might be due to the mixing of ethanol and water which promoted the supersaturating of the system [28].

\subsubsection{Effect of extraction time on extraction yield of SGP}

Longer extraction time would express a positive effect on extraction yield of SGP. In this test, different extraction time was under $30 \mathrm{~min}, 40 \mathrm{~min}, 50 \mathrm{~min}, 60$ min and 70 min with the $65 \%$ ethanol on $75^{\circ} \mathrm{C}$ under the ultrasound power of $320 \mathrm{~W}$. It can be seen from Fig. 2 (B) that the extraction yield of SGP increased significant $(P<0.05)$ with the extraction time from $30 \mathrm{~min}$ to $70 \mathrm{~min}$. The extraction rate of the SGP did not change with the extension time after $60 \mathrm{~min}$, which may because that it was basically dissolved [27] in the solvent at about $1.96 \pm 0.06 \%$.

\subsubsection{Effect of ultrasound assisted power on extraction yield of $S G P$}

Ultrasound assisted power was an important factor to affect the extraction yield of SGP obviously. In the experiments, the ultrasound power was set with $100 \mathrm{~W}$, $200 \mathrm{~W}, 320 \mathrm{~W}$, and $400 \mathrm{~W}$ as the SGP was reflected at $75^{\circ} \mathrm{C}$ for 60 min with ethanol volume fraction of $65 \%$. It can be seen from Fig. 2 (C) that the extraction yield of SGP increased significant $(P<0.05)$ with the increasing ultrasound power, which the maximum value was consistently remained at $1.87 \pm 0.06 \%$. It might be dissolved more completely under the action of ultrasonic power $(320 \mathrm{~W})$. Conversely, excessive power would cause the glycosidic bond broken, which might increase the destruction of SGP.

Table 1 Design and results of response surface experiments for the yield response

\begin{tabular}{llllll}
\hline \multirow{2}{*}{ Experiments } & \multicolumn{4}{c}{ Factors } & $\begin{array}{c}\text { Response } \\
\text { Yield } \\
(\%)\end{array}$ \\
\cline { 2 - 5 } & $\begin{array}{l}\mathrm{X}_{\mathrm{a}} \text { : Ethanol volume } \\
\text { fraction (\%) }\end{array}$ & $\begin{array}{l}\mathrm{X}_{\mathrm{b}} \text { : Time } \\
(\mathrm{min})\end{array}$ & $\begin{array}{l}\mathrm{X}_{\mathrm{c}} \text { : Ultrasound } \\
\text { power }(\mathrm{W})\end{array}$ & $\begin{array}{l}\mathrm{X}_{\mathrm{d}}: \\
\text { Temperature } \\
\left({ }^{\circ} \mathrm{C}\right)\end{array}$ & $\begin{array}{l}75(0) \\
0\end{array}$ \\
\hline 1 & $80(1)$ & $60(0)$ & $440(1)$ & $65(-1)$ & 1.99 \\
2 & $65(0)$ & $50(-1)$ & $320(0)$ & $75(0)$ & 1.76 \\
3 & $80(1)$ & $60(0)$ & $200(-1)$ & & \\
\hline
\end{tabular}

\subsubsection{Effect of extraction temperature on extraction yield of SGP}

To ensure the influence of extraction temperature on yield of SGP, the extraction temperature of $50^{\circ} \mathrm{C}, 65^{\circ} \mathrm{C}$, $75^{\circ} \mathrm{C}$ and $85^{\circ} \mathrm{C}$ was investigated in this study, as shown in Fig.2 (D). The extraction time and ethanol volume fraction were reflected for $60 \mathrm{~min}$ with $65 \%$ at the $320 \mathrm{~W}$ of ultrasound power. From $50^{\circ} \mathrm{C}$ to $85^{\circ} \mathrm{C}$, the total extraction yield of SDF was correlated significant $(P<0.05)$ with the extraction temperature. The total extraction yield of SGP reached a maximum of $1.89 \%$ when the extraction temperature reached $75^{\circ} \mathrm{C}$. This situation might be because the high temperature caused its decomposition.

\subsection{Optimization of extraction parameters of SGP}

\subsubsection{Statistical analysis and model fitting}

As shown in the Table 1, the data of fitted quadratic multiple regression equation is analyzed by DesignExpert (V8.0.6) as follows:

$Y(\%)=2.07+0.057 X_{a}+0.081 X_{b}+0.12 X_{c}+0.12 X_{d}+5.000 E-$ $003 X_{a} X_{b}-0.020 X_{a} X_{c}$

$+0.030 X_{a} X_{d}+0.045 X_{b} X_{c}+0.027 X_{b} X_{d}+0.040 X_{c} X_{d}-0.21 X_{a}^{2}-$ $0.065 X_{b}^{2}-0.071 X_{c}^{2}-0.067 X_{d}^{2}$.

The detailed results about the significance analysis of the binomial regression model coefficients in this experiment were calculated in Table 2 . The low P-value $(P<0.0001)$ indicated that the model was significant on yield of polysaccharide at $95 \%$ confidence. The Lack of fit $(P=0.6317)$ indicated that the model was fitted well and the error of the experimental value was relatively small. The high model determination coefficient $\left(R^{2}=0.9499\right)$ indicated the regression equation can be used to analyze and predict the results. In addition, the model coefficient of variation $(C V)$ was $5.36 \%$, we can concluded that the test can be used for statistical analysis. The factors of $\mathrm{X}_{\mathrm{a}}, \mathrm{X}_{\mathrm{b}}, \mathrm{X}_{\mathrm{c}}, \mathrm{X}_{\mathrm{d}}$ and $\mathrm{X}_{\mathrm{a}}{ }^{2}$ had extremely significant $(P<0.0001)$ effect on the yield of polysaccharides, while quadratic terms $X_{b}{ }^{2} 、 X_{c}{ }^{2}$ and $X_{d}{ }^{2}$ reached significant $(P<0.01)$ levels. The significant between $X_{a} X_{c}, X_{b} X_{c}$ and $X_{c} X_{d}$ were considerable. The importance degree of each factor was listed as follows: ultrasound assisted power $>$ extraction temperature $>$ extraction time $>$ ethanol volume fraction. 


\begin{tabular}{llllll}
\hline 4 & $65(0)$ & $50(-1)$ & $200(-1)$ & $75(0)$ & 1.78 \\
5 & $65(0)$ & $50(-1)$ & $440(1)$ & $75(0)$ & 1.99 \\
6 & $50(-1)$ & $60(0)$ & $320(0)$ & $65(-1)$ & 1.69 \\
7 & $65(0)$ & $60(0)$ & $440(1)$ & $85(1)$ & 2.15 \\
8 & $65(0)$ & $60(0)$ & $440(1)$ & $65(-1)$ & 1.81 \\
9 & $65(0)$ & $60(0)$ & $320(0)$ & $75(0)$ & 2.16 \\
10 & $50(-1)$ & $60(0)$ & $200(-1)$ & $75(0)$ & 1.57 \\
11 & $80(1)$ & $60(0)$ & $320(0)$ & $85(1)$ & 1.73 \\
12 & $50(-1)$ & $60(0)$ & $320(0)$ & $85(1)$ & 1.83 \\
13 & $65(0)$ & $60(0)$ & $320(0)$ & $75(0)$ & 2.02 \\
14 & $65(0)$ & $60(0)$ & $320(0)$ & $75(0)$ & 2.03 \\
15 & $50(-1)$ & $60(0)$ & $440(1)$ & $75(0)$ & 1.88 \\
16 & $50(-1)$ & $70(1)$ & $320(0)$ & $75(0)$ & 1.81 \\
17 & $80(1)$ & $50(-1)$ & $320(0)$ & $75(0)$ & 2.19 \\
18 & $65(0)$ & $70(1)$ & $320(0)$ & $85(1)$ & 1.91 \\
19 & $65(0)$ & $60(0)$ & $200(-1)$ & $85(1)$ & 1.87 \\
20 & $65(0)$ & $70(1)$ & $320(0)$ & $65(-1)$ & 1.91 \\
21 & $80(1)$ & $70(1)$ & $320(0)$ & $75(0)$ & 1.63 \\
22 & $50(-1)$ & $50(-1)$ & $320(0)$ & $75(0)$ & 1.99 \\
23 & $80(1)$ & $60(0)$ & $320(0)$ & $85(1)$ & 1.82 \\
24 & $65(0)$ & $70(1)$ & $200(-1)$ & $75(0)$ & 2.04 \\
25 & $65(0)$ & $60(0)$ & $200(-1)$ & $65(-1)$ & 1.97 \\
26 & $65(0)$ & $60(0)$ & $320(0)$ & $75(0)$ & 2.09 \\
27 & $65(0)$ & $50(-1)$ & $320(0)$ & $85(1)$ & 2.21 \\
28 & $65(0)$ & $60(0)$ & $320(0)$ & $75(0)$ & $75(0)$ \\
29 & $65(0)$ & $70(1)$ & $440(1)$ & 73 \\
\hline
\end{tabular}

Table 2 The analysis of variance (ANOVA) of the regression model for the yield response

\begin{tabular}{lllll}
\hline Variable & Yield $(\%)$ & & & \\
\cline { 2 - 4 } & SS & DF & F-value & P-value \\
\hline Model & 0.79 & 14 & 18.97 & $<0.0001^{\mathrm{b}}$ \\
$\mathrm{X}_{\mathrm{a}}$ & 0.039 & 1 & 13.00 & $0.0029^{\mathrm{a}}$ \\
$\mathrm{X}_{\mathrm{b}}$ & 0.078 & 1 & 26.45 & $<0.0001^{\mathrm{b}}$ \\
$\mathrm{X}_{\mathrm{c}}$ & 0.18 & 1 & 59.92 & $<0.0001^{\mathrm{b}}$ \\
$\mathrm{X}_{\mathrm{d}}$ & 0.18 & 1 & 59.10 & $<0.0001^{\mathrm{b}}$ \\
$\mathrm{X}_{\mathrm{a}} \mathrm{X}_{\mathrm{b}}$ & 0.156 & 1 & 0.034 & 0.1569 \\
$\mathrm{X}_{\mathrm{a}} \mathrm{X}_{\mathrm{c}}$ & 0.056 & 1 & 0.54 & 0.0047 \\
$\mathrm{X}_{\mathrm{a}} \mathrm{X}_{\mathrm{d}}$ & 0.034 & 1 & 1.21 & 0.0891 \\
$\mathrm{X}_{\mathrm{b}} \mathrm{X}_{\mathrm{c}}$ & 0.035 & 1 & 2.73 & 0.0006 \\
$\mathrm{X}_{\mathrm{b}} \mathrm{X}_{\mathrm{d}}$ & 0.215 & 1 & 1.02 & 0.3296 \\
$\mathrm{X}_{\mathrm{c}} \mathrm{X}_{\mathrm{d}}$ & 0.176 & 1 & 2.16 & 0.0039 \\
$\mathrm{X}_{\mathrm{a}}{ }^{2}$ & 0.28 & 1 & 95.19 & $<0.0001^{\mathrm{b}}$ \\
$\mathrm{X}_{\mathrm{b}}{ }^{2}$ & 0.027 & 1 & 9.20 & $0.0090^{\mathrm{a}}$ \\
$\mathrm{X}_{\mathrm{c}}{ }^{2}$ & 0.033 & 1 & 11.06 & $0.0050^{\mathrm{a}}$ \\
$\mathrm{X}_{\mathrm{d}}{ }^{2}$ & 0.029 & 1 & 9.92 & \\
Residual & 0.042 & 14 & & 0.6317 \\
Lack of Fit & 0.028 & 10 & & \\
Pure Error & 0.013 & 4 & 0.63 & \\
Cor Total & 0.83 & 28 & & \\
C.V.(\%) & 5.36 & & & \\
\hline
\end{tabular}

a Significant at 0.001 level.

${ }^{\mathrm{b}}$ Significant at 0.01 level.

\subsubsection{Analysis of response surface}

The best region to examine the interaction was reflected by the three-dimensional response surface with Designexpert (V12) software between every two factors. The optimal extraction conditions were obtained by determining the slope of the three-dimensional map and the degree of circularity of the contour map in Fig. 3. It can be judged that the bending of the six groups of three- dimensional images was relatively large according to the design principle of the response surface test. So, it reflected the extraction effect of the polysaccharide was also significantly different. Therefore, the optimal isolation parameters were as follows: ethanol volume fraction was $65 \%$, extraction time was $72 \mathrm{~min}$, ultrasound assisted power was $438 \mathrm{~W}$, and temperature was $85^{\circ} \mathrm{C}$. 
(a)

(d)
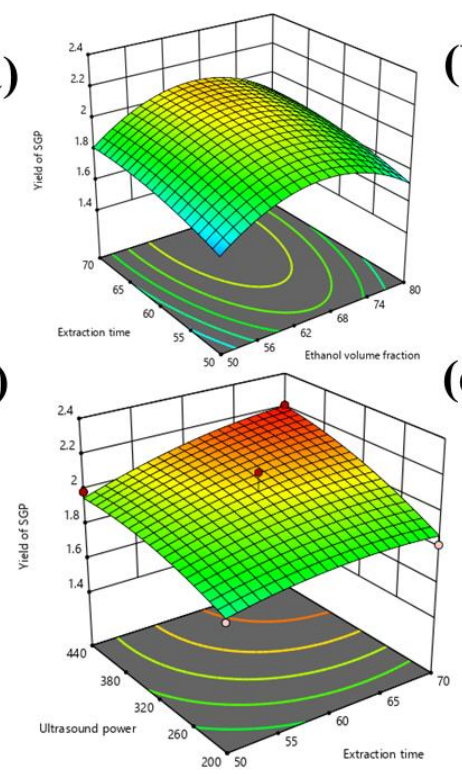

(b)

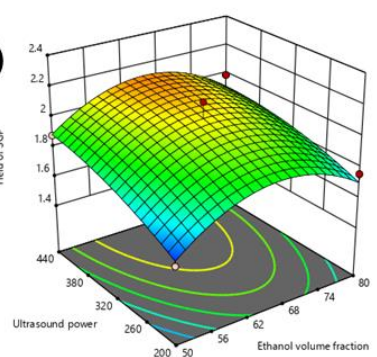

(e)

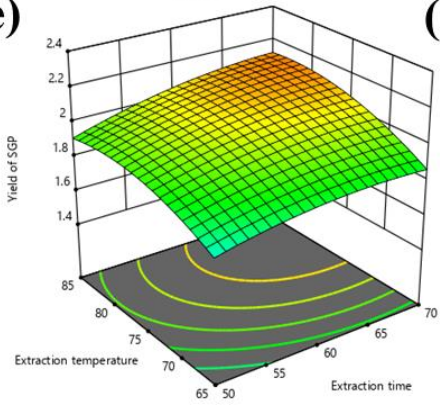

(c)

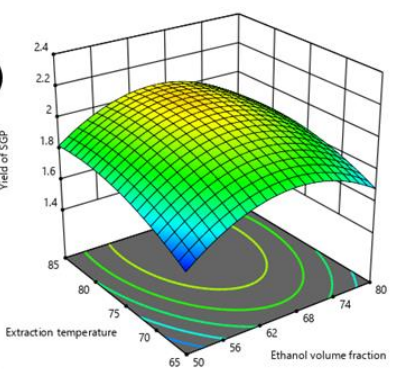

(f)

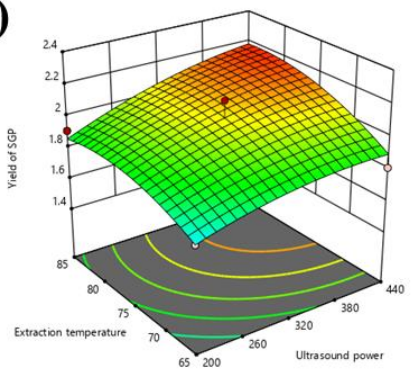

Fig.3 Response surface plots of the interaction of various factors on the yield of SGP. (a)The factors of time (min) and ethanol volume fraction (\%). (b) The factors of ethanol volume fraction (\%) and ultrasound power (W). (c)The factors of ethanol volume fraction $(\%)$ and temperature $\left({ }^{\circ} \mathrm{C}\right)$. (d) The factors of time $(\mathrm{min})$ and ultrasound power $(\mathrm{W})$. (e)The factors of temperature $\left({ }^{\circ} \mathrm{C}\right)$ and time (min). (f) The factors of temperature $\left({ }^{\circ} \mathrm{C}\right)$ and ultrasound power $(\mathrm{W})$.

\subsection{Purification and characterization of SGP}

\subsubsection{Purification of crude SGP}

As shown in Fig. 4, crude SGP was purified by DEAE-

52 cellulose column to obtain SGP-1 $(0.2 \mathrm{M} \mathrm{NaCl})$ and
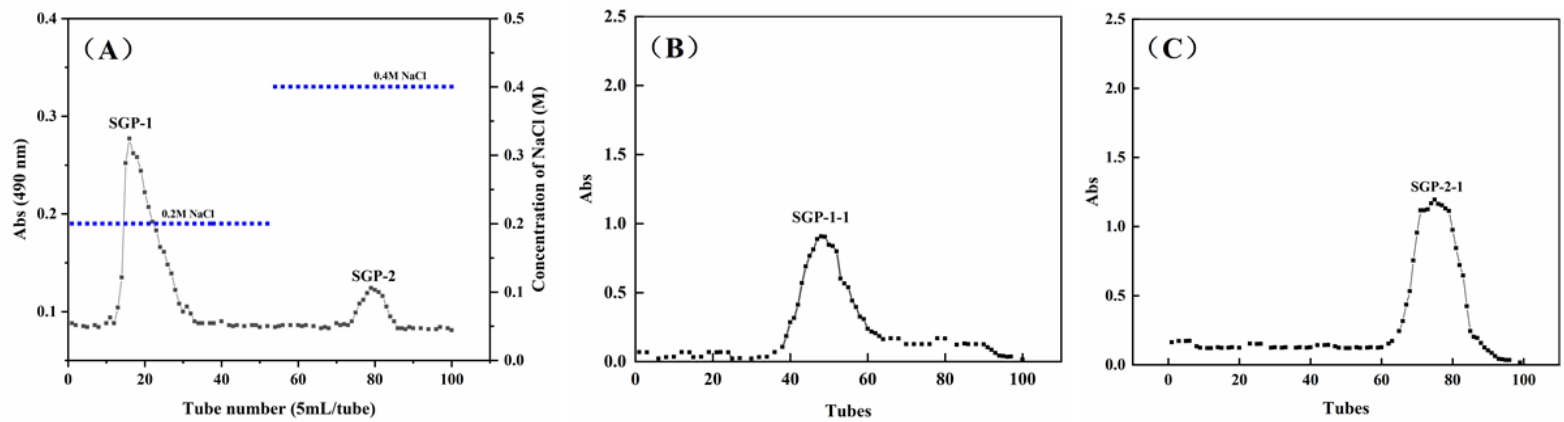

Fig.4 Elution curve of crude SGP on DEAE-52 cellulose chromatography column (A) and elution curves of SGP-1 (B) and SGP-2 (C) on Sephadex G-100 chromatography column, respectively.

\subsubsection{Composition and chemical property of SGP}

Table 3 Composition of crude SGP and pure SGP

\begin{tabular}{llll}
\hline Items & Crude SGP & SGP-1-1 & SGP-2-1 \\
\hline Protein (\%) & $1.12 \pm 0.06$ & - & - \\
$\begin{array}{l}\text { Carbohydrate (\%) } \\
\text { Total flavonoid } \\
\text { (mg GAE/100 mg) }\end{array}$ & $52.31 \pm 2.02^{\mathrm{a}}$ & $79.01 \pm 2.71^{\mathrm{b}}$ & $77.15 \pm 2.21^{\mathrm{c}}$ \\
Uronic acid (\%) & $2.16 \pm 0.08$ & - & - \\
\hline
\end{tabular}

- was not detected and the different lowercases indicated significant difference $\left(\mathrm{P}_{b}<0.05\right)$ in the same line.

The contents of carbohydrates, proteins, uronic acids and total flavonoids in crude SGP and purified SGP samples were summarized in Table 3 . The results indicated that the higher content of these samples was carbohydrate, which were $52.31 \pm 0.02 \%, 79.01 \pm 2.71 \%$, and $77.15 \pm 2.21 \%$, respectively. The crude SGP contained lower uronic acid content $(7.15 \pm 0.15 \%)$ while it was absent of protein $(1.12 \pm 0.06 \%)$. The phenomenon 
of this difference in composition indicated that the savage produced good deproteinization effect. In addition, the lack of flavonoids detection in the pure
SGP determined the independence of the antioxidants of the polysaccharides.
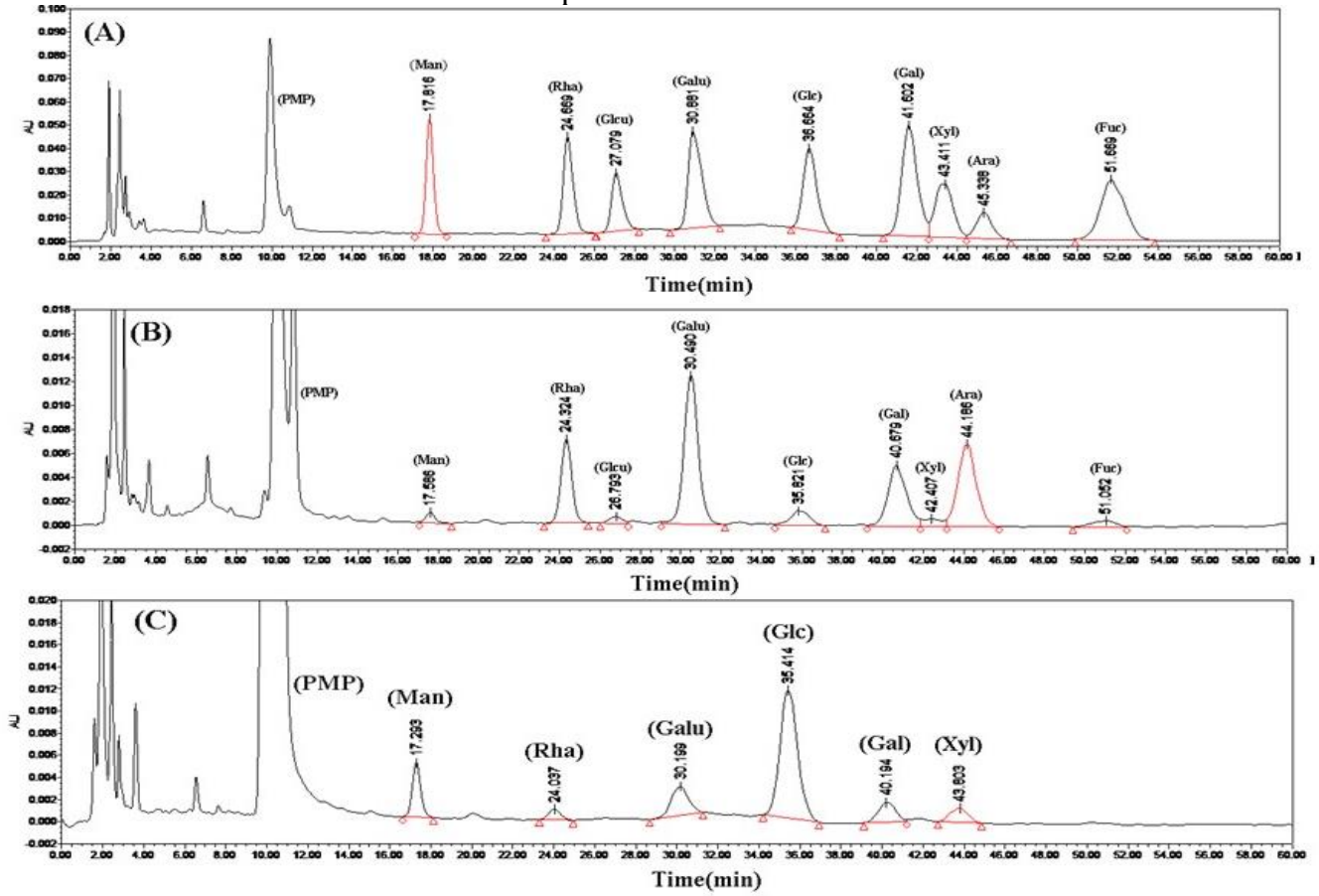

Fig.6 FPLC of crude SGP (A), SGP-1-1 (B) and SGP-2-1(C) (glucose : Glc, mannose: Man, xylose: Xyl, galacturonic acid: Galu, glucuronic acid: Glcu, fucose: Fuc, rhamnose: Rha, arabinose: Ara and galactose: Gal).

\subsubsection{Monosaccharide composition and molecular weight of SGP}

The monosaccharide composition analysis of SGP was performed by area normalization of HPLC. Totally, the molecular weight of crude SGP, SGP-1-1 and SGP-2-1 were $6.6 \times 10^{5} \mathrm{~g} / \mathrm{mol}, 3.27 \times 10^{5} \mathrm{~g} / \mathrm{mol}$ and $2.89 \times 10^{5}$ $\mathrm{g} / \mathrm{mol}$, respectively. The main particle size distribution was shown in Fig. 5. The chromatogram of 9 monosaccharide standards showed that peaks were collected within $65 \mathrm{~min}$ named as glucose, mannose, xylose, galacturonic acid, glucuronic acid, fucose, rhamnose, arabinose, galactose, as shown in Fig. 6 (A), respectively. Then, peaks were determined by matching their retention times to that of standards. SGP-1-1 included 9 monosaccharides, at the molar ratio of 0.27 : 0.85: 0.21: 2.13: 0.63: 0.92: 0.23: $1.15: 0.43$ in Fig. 6(B), respectively. SGP-2-1 contained 6 monosaccharides, namely glucose, mannose, galacturonic acid, glucuronic acid, fucose, arabinose, at the molar ratio of 0.83: 0.42: 0.56: 1.87: 0.61: 0.63 in Fig. $6(\mathrm{C})$. This result was some different from previous reports on blackberry polysaccharides [려]. The reasons may be closely related to the growth environment of the plants as well as the extraction and purification methods.

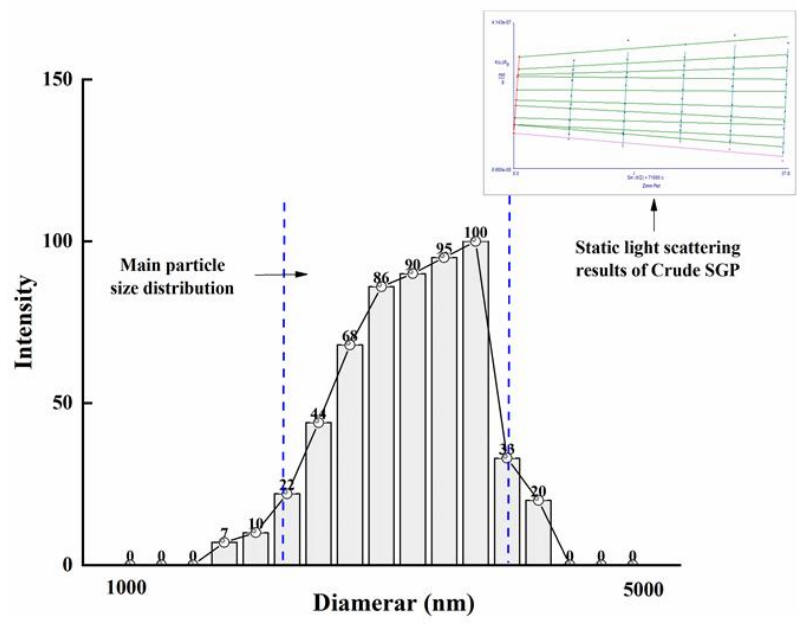

Fig.5 Molecular weight and particle size distribution of crude SGP.

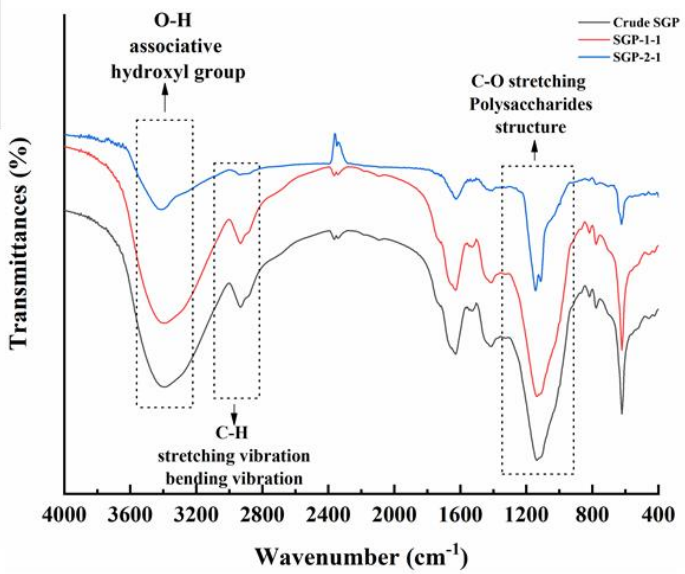

Fig.7 FT-IR spectra of SGP 


\subsubsection{FT-IR spectrum and SEM of SGP}

The IR analysis spectrum of the polysaccharide was shown in Fig. 7. The broad peak at around $3400 \mathrm{~cm}^{-1}$ (SGP-1-1:3365 $\mathrm{cm}^{-1}$, SGP-2-1:3438 $\mathrm{cm}^{-1}$ ) were belonged to $\mathrm{O}-\mathrm{H}$ of associative hydroxyl group, and the peak around $2939 \mathrm{~cm}^{-1}$ (SGP-1-1: $2900 \mathrm{~cm}^{-1}$, SGP-2-1:2988 $\mathrm{cm}^{-1}$ ) were attributed to $\mathrm{C}-\mathrm{H}$ stretching vibration and bending vibration. The absorption peak at $1424 \mathrm{~cm}^{-1}$ (SGP-1-1:1420 $\mathrm{cm}^{-1}$, SGP-2-1:1412 $\mathrm{cm}^{-1}$ ) belonged to the $\mathrm{C}-\mathrm{O}-\mathrm{H}$ carboxy symmetric stretching vibration, which was ascribed to the uronic acid groups of the polysaccharide [30]. The absorption band on the polysaccharide at $1615 \mathrm{~cm}^{-1}$ (SGP-1-1:1612 $\mathrm{cm}^{-1}$, SGP2-1:1623 $\mathrm{cm}^{-1}$ ) were due to the $\mathrm{C}=\mathrm{O}$ group [31]. The peak at $1022 \mathrm{~cm}^{-1}$ (SGP-1-1:1012 $\mathrm{cm}^{-1}$, SGP-2-1:1020 $\mathrm{cm}^{-1}$ ) were attributed to the $\mathrm{C}-\mathrm{O}-\mathrm{H}$ deformation vibration. The adsorption band at $1099 \mathrm{~cm}^{-1}$ (SGP-1-1:1071 cm-1, SGP-2-1:1054 $\mathrm{cm}^{-1}$ ) belonged to the C-O-C stretching vibration of the pyranose pentacyclic ring [32]. It indicated the existence of the glycosidic bond contained in pyranose ring. Additionally, the absorption peak at about $890 \mathrm{~cm}^{-1}$ (SGP-1-1:894 $\mathrm{cm}^{-1}$, SGP-2-1:897 $\mathrm{cm}^{-1}$ ) suggested that $\beta$-configuration was contained in this sugar structure [33] . Therefore, all these results showed the presence of the characteristic groups of the polysaccharide.

It can be seen from Fig. 8 that the surface of the SGP had a clear pore structure when the magnification was $20.0 \mathrm{~K}$, while it was spherical with a viscosity wire under the magnification of $40.0 \mathrm{~K}$ and $50.0 \mathrm{~K}$. The reason for these phenomena may due to that SGP was broken into small molecule polysaccharides under ultrasound [23], and the apparent structural properties leaded to its higher solubility [34]. In addition, the deproteinization operation also played an important factor on the rough pore structure of the polysaccharide surface[35]. Besides, the alone component polysaccharide appearance after purification including SGP-1-1 and SGP-2-1 can be clearly observed at 50.0 K. The SGP-1-1 and SGP-2-1 lacked protein filament when we compared with the shape of crude polysaccharide. The reason for this phenomenon may be that the polysaccharide was more purify after cellulose chromatography.

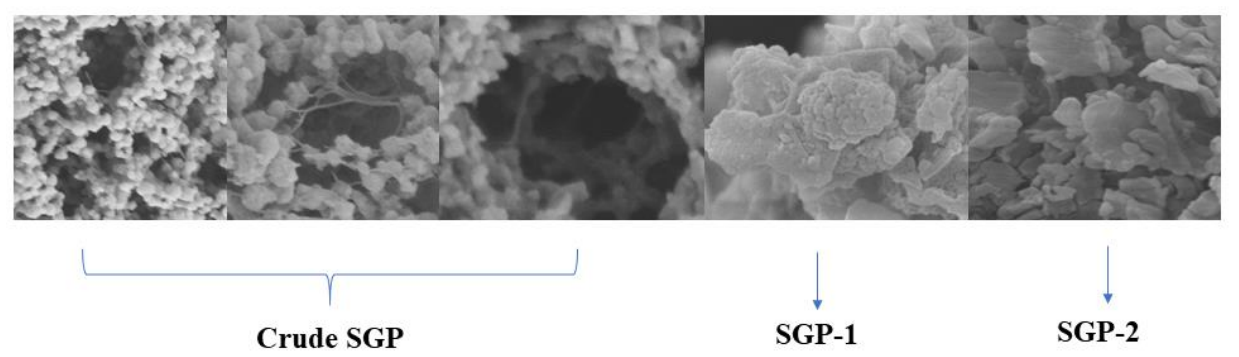

Fig. 8 SEM of SGP

\subsection{Antioxidant activities in vitro of SGP}

\subsubsection{DPPH free radical scavenging activity of SGP}

The principle of DPPH free radical scavenging activity depended on the disappeared absorption peak at $517 \mathrm{~nm}$, when a free radical scavenger paired with the DPPH radical single electron, and therefore can be performed to analyze its oxidation by spectrophotometers rapidly [24]. As shown in Fig. 9 (A), it can be seen that the crude SGP exhibited a significant $(P<0.05)$ dose-dependent effect on better free radical scavenging ability in the concentration range from 0.2 to $4.0 \mathrm{mg} / \mathrm{mL}$. The DPPH free radical scavenging activities was $55.21 \pm 2.5 \%$, it was 0.61 times that of the standard of $\mathrm{VC}$ at the concentration of $4.0 \mathrm{mg} / \mathrm{mL}$, where the $\mathrm{IC}_{50}$ of crude SGP was $0.16 \mathrm{mg} / \mathrm{mL}$. The scavenging ability of SGP-11 and SGP-2-1 expressed lower than that of crude SGP at the same polysaccharide concentration. All of the three groups showed a dose-dependent effect. These phenomena involved in the experiment might due to SGP which can be seen as an electron provider to scavenge DPPH. The color of the system was changed when the electrons provided by the polyhydroxy structure of the polysaccharide connected with the DPPH radical electrons. This method precisely simulated the state of competition with the body for DPPH free radicals.

\subsection{2 $\mathrm{ABTS}^{+}$radical scavenging activity of SGP}

The absorbance of $\mathrm{ABTS}^{+}$can be determined at $734 \mathrm{~nm}$ to calculate the total antioxidant capacity of the samples. Green $\mathrm{ABTS}^{+}$provided by ABTS under the action of oxidant when the production of $\mathrm{ABTS}^{+}$were inhibited in the presence of antioxidants [36]. The lighter the color of the reaction system, the higher the antioxidant capacity confirmed. As shown in Fig.9 (B), the $\mathrm{ABTS}^{+}$radical scavenging activity were positively correlated $(P<0.05)$ with the sample concentration range. The crude SGP radical scavenging activity of $\mathrm{ABTS}^{+}$was higher than SGP-1-1 and SGO-2-1 at every concentration, which was $93.45 \pm 1.5 \%$ at the concentration of $4.0 \mathrm{mg} / \mathrm{mL}$, respectively, and the $\mathrm{IC}_{50}$ of $\mathrm{VC}$ was 2.75 times higher than that of crude SGP. SGP-2-1 showed the worst oxidation resistance when we compared these three groups except for the control. It probably because it lacked fucose which possessed stronger [37] effect than SGP-1-1. The ABTS ${ }^{+}$free radical scavenging activity of SGP might depend on their structural integrity and 
molecular size, which was no different from previous reports $[\underline{38}, \underline{39}]$

\subsubsection{Hydroxyl radical scavenging activity of SGP}

Gene transcriptional expression process was blocked when the hydroxyl group rapidly reacted with intracellular DNA across the biofilm system. This phenomenon caused by hydroxyl groups which would result in apoptosis and tissue damage. Therefore, removing the hydroxyl radicals was the main protection for the living system. As shown in Fig. 9 (C), the hydroxyl radical scavenging activity of SGP was
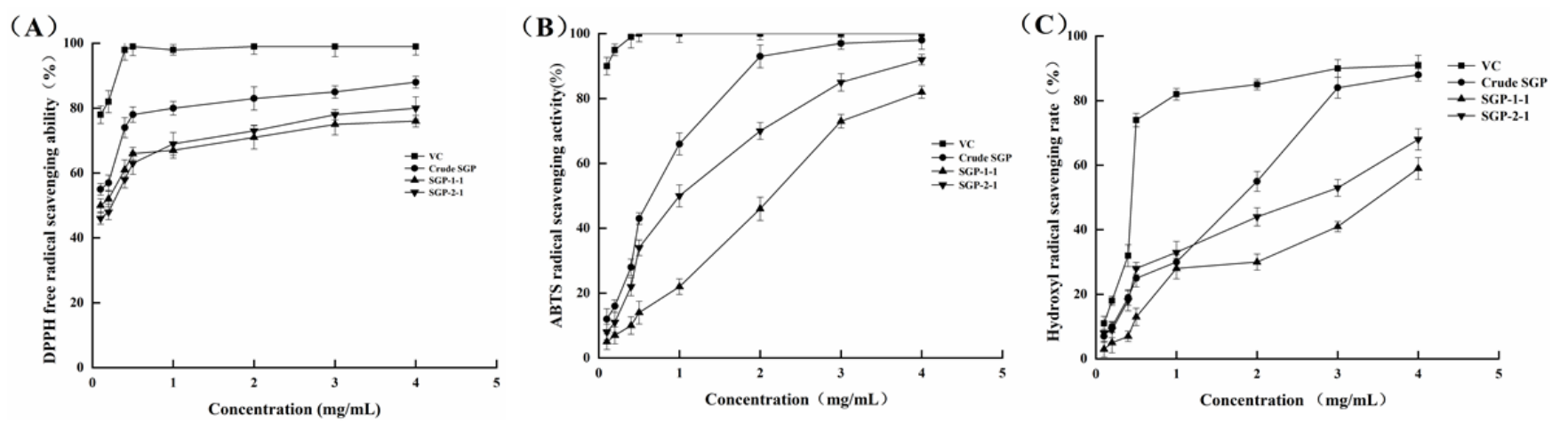

Fig.9 Antioxidant activities on DPPH free radical scavenging activity, ABTS+ radical scavenging activity and hydroxyl radical scavenging activity of VC, crude SGP, SGP-1-1 and SGP-2-1. Values were present as means \pm SD.

\section{Conclusion}

In this study, the SGP was purified after extraction with hot water assisted by ultrasound from Suaeda salsa. BBD was adopted to increase the extraction yield of SGP, and the optimal conditions were obtained as follows: ethanol volume fraction was $65 \%$, extraction time was $72 \mathrm{~min}$, ultrasound assisted power was $438 \mathrm{~W}$, and temperature was $85^{\circ} \mathrm{C}$, respectively. It was coincided with the model predictions under these conditions, which the extraction yield of SGP was $2.19 \pm$ $0.13 \%$. The crude SGP was purified with DEAE-52 cellulose and Sephadex G-100 into SGP-1-1 and SGP-21. Crude SGP provided higher significant potentials $(\mathrm{P}<0.05)$ in scavenging ability against DPPH, $\mathrm{ABTS}^{+}$ and hydroxyl radical under the optimized conditions. including the molar ratio of crude SGP, SGP-1-1 and SGP-2-1 were measured, respectively. Besides, both SEM and FT-IR clearly showed that the characteristic structure of SGP was viscous polysaccharide with uronic acid groups, which means that the polysaccharide could gives viscous solution. Thus, it can be used as a natural antioxidant source with good development prospects, and further study should concentrate on the use of polysaccharide in nutrition food in the future.

\section{Acknowledgement}

We are deeply grateful for the support of National Natural Science Foundation of China (No. 21705084), and the Natural Science Foundation of Shandong Meanwhile, the monosaccharide composition analysis concentration dependent. The VC scavenging activity of hydroxyl was $93.24 \pm 2.1 \%$ at the concentration of 4.0 $\mathrm{mg} / \mathrm{mL}$, as the $\mathrm{IC}_{50}$ was $0.32 \mathrm{mg} / \mathrm{mL}$. The trend changes of the three groups were distinguished at $1.0 \mathrm{mg} / \mathrm{mL}$. For example, crude SGP had opposite trend when the concentration was greater than $1.0 \mathrm{mg} / \mathrm{mL}$, compared with SGP-1-1 and SGP-2-1. At the same time, SGP-1-1 and SGP-2-1 also expressed dose-dependent effects. The factor for this phenomenon may be explained by that SGP provided a amount of active hydroxyl groups from polysaccharides under low temperature treatment, which was consistent with previous reports [40].
Province of China (No. ZR2017BB074), National Training Program of Innovation and Entrepreneurship for Undergraduates (No. 201710431040), Special Funds for Taishan Scholars Project, and Master's Funded project of Jinan University laboratory.

\section{Compliance with ethics guidelines}

The authors declare that they have no conflict of interest.

This article does not contain any studies with human or animal subjects performed by any of the authors.

\section{References}

1. Benwahhoud M, Jouad H, Eddouks M, Lyoussi B Journal of Ethnopharmacology. 76, 35-38 (2001)

2. Bartolozzi F, Bertazza G, Bassi D, Cristoferi G Journal of Chromatography A. 758, 99-107 (1997)

3. Leone S, Molinaro A, Dubery I, Lanzetta R, Parrilli M Carbohydr Res. 342, 1514-1518 (2007)

4. Costa L S, Fidelis G P, Cordeiro S L, Oliveira R M, Sabry D A, Camara R B G, Nobre L T D B, Costa M S S P, Almeida-Lima J, Farias E H C, Leite E L, Rocha H A O Biomedicine \& Pharmacotherapy. 64, 21-28 (2010)

5. Okoli C O, Akah P A Pharmacol Biochem Behav. 79, 473-481 (2004)

6. Amir M, Shikha K European Journal of Medicinal Chemistry. 39, 535-545 (2004)

7. Ralet M C, Andre-Leroux G, Quemener B, Thibault J F Phytochemistry. 66, 2800-2814 (2005) 
8. Shakhmatov E G, Toukach P V, Michailowa C, Makarova E N Carbohydr Polym. 113, 515-524 (2014)

9. Thambiraj S R, Phillips M, Koyyalamudi S R, Reddy N Industrial Crops and Products. 74, 950-956 (2015)

10. Zhang J, Wen C, Chen M, Gu J, Zhou J, Duan Y, Zhang H, Ma H Int J Biol Macromol. 134, 172-179 (2019)

11. Xiang B, Yu X, Li B, Xiong Y, Long M, He Q J Food Biochem. 43, e12899 (2019)

12. Li S, Wang A, Liu L, Tian G, Xu F Food Sci Biotechnol. 28, 759-767 (2019)

13. Tang C, Ding R, Sun J, Liu J, Kan J, Jin C Food Funct. 10, 2290-2312 (2019)

14. Scroccarello A, Della Pelle F, Neri L, Pittia P, Compagnone D Food Res Int. 119, 359-368 (2019)

15. Della Pelle F, Scroccarello A, Scarano S, Compagnone D Anal Chim Acta. 1051, 129-137 (2019)

16. Wu D T, Liu W, Han Q H, Du G, Li H Y, Yuan Q, Fu Y, Zhao L, Zhang Q, Li S Q, Qin W Int J Biol Macromol. 136, 891-900 (2019)

17. Abou El Azm N, Fleita D, Rifaat D, Mpingirika E Z, Amleh A, El-Sayed M M H Molecules. 24, (2019)

18. Chen C, Wang P P, Huang Q, You L J, Liu R H, Zhao M M, Fu X, Luo Z G Food Funct. 10, 36843695 (2019)

19. Pu X, Ma X, Liu L, Ren J, Li H, Li X, Yu S, Zhang W, Fan W Carbohydr Polym. 137, 154-164 (2016)

20. Wang Z-B, Chen B-B, Luo L, Yan J-K Journal of the Taiwan Institute of Chemical Engineers. 67, 5460 (2016)

21. Hammi K M, Hammami M, Rihouey C, Le Cerf D, Ksouri R, Majdoub H Food Chemistry. 212, 476484 (2016)

22. Yuan Q, Xie Y, Wang W, Yan Y, Ye H, Jabbar S, Zeng X Carbohydr Polym. 128, 52-62 (2015)

23. Wefers D, Gmeiner B M, Tyl C E, Bunzel M Phytochemistry. 116, 320-328 (2015)

24. Chen R-Z, Tan L, Jin C-G, Lu J, Tian L, Chang Q-Q, Wang K Industrial Crops and Products. 77, 434-443 (2015)

25. Wang Y, Wang F, Ma X, Sun S, Leng F, Zhang W, Wang X Industrial Crops and Products. 77, 467-475 (2015)

26. Ben Salem Y, Amri S, Hammi K M, Abdelhamid A, Le Cerf D, Bouraoui A, Majdoub H International Journal of Biological Macromolecules. 97, 8-15 (2017)

27. Ballesteros L F, Teixeira J A, Mussatto S I Carbohydrate Polymers. 157, 258-266 (2017)

28. Mzoughi Z, Abdelhamid A, Rihouey C, Le Cerf D, Bouraoui A, Majdoub H Carbohydr Polym. 185, 127-137 (2018)
29. Yin J Y, Nie S P, Zhou C, Wan Y, Xie M Y J Sci Food Agric. 90, 210-217 (2010)

30. Jiang Y Y, Wang L, Zhang L, Wang T, Yu L, Ding C B, Yang R W, Wang X L, Zhou Y H Int J Biol Macromol. 70, 92-99 (2014)

31. Zhao Y M, Song J H, Wang J, Yang J M, Wang Z B, Liu Y H J Sci Food Agric. 96, 4484-4491 (2016)

32. Ono Y, Furihata K, Isobe N, Saito T, Isogai A Int J Biol Macromol. 107, 2598-2603 (2018)

33. Zhao T, Mao G, Feng W, Mao R, Gu X, Li T, Li Q, Bao Y, Yang L, Wu X Carbohydr Polym. 105, 2633 (2014)

34. Sun Y, Cui S W, Tang J, Gu X Carbohydrate Polymers. 80, 544-550 (2010)

35. You Q, Yin X, Zhang S, Jiang Z Carbohydr Polym. 99, 1-10 (2014)

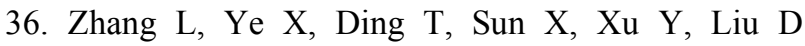
Ultrason Sonochem. 20, 222-231 (2013)

37. Zhu X, Li W, Li Y, Xu W, Yuan Y, Zheng V, Zhang $\mathrm{H}$, O'Donnell $\mathrm{J} \mathrm{M}, \mathrm{Xu} \mathrm{Y}$, Yin $\mathrm{X}$ Neuropharmacology. 153, 20-31 (2019)

38. Zhang S, Yi X, Su X, Jian Z, Cui T, Guo S, Gao T, Li C, Li S, Xiao Q J Cell Mol Med.74, (2019)

39. Russo D, Faraone I, Labanca F, Sinisgalli C, Bartolo M, Andrade P B, Valentao P, Milella L Phytochem Anal. 84, (2019)

40. Foyer C H, Pellny T K, Locato V, Hull J, De Gara L Methods Mol Biol. 1990, 165-181 (2019) 